\title{
Claves para repensar los medios y el mundo que habitamos
}

\section{Keys to rethink the media and the World we inhabit}

Fechas | En edición: 23/01/2021 - Publicación final: 01/07/2021

\section{Lara María ESPINAR}

Universidad de Málaga. España. espinarmedina@gmail.com

https://orcid.org/0000-0003-2822-3663

\section{Claves para repensar los medios y el mundo que habitamos. La distopía del desarrollo}

Autor: Manuel CHAPARRO-ESCUDERO

Bogotá: Desde Abajo, 2015

294 páginas

ISBN: 978-95-858826-0-7

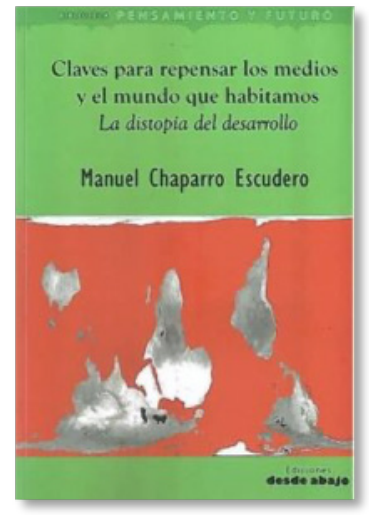

\section{Resumen}

Distopía, "representación ficticia de una sociedad futura de características negativas causantes de la alineación humana" (Real Academia de la Lengua Española). Esta es la palabra que Manuel Chaparro, con matemática precisión, escoge para el título de su obra: "Claves para repensar los medios y el mundo que habitamos. La distopía del desarrollo". Para el autor desarrollo es mucho más que un término, se trata de todo un sistema complejo cuyo carácter distópico va desenmascarando a través de las páginas de este libro, que nos ofrece una perspectiva de análisis de la realidad y la evolución que hemos tenido como civilización desde el ámbito de la comunicación. Un libro que nos habla de cómo la información y la comunicación han construido, difundido e implantado los imaginarios del Modelo de Desarrollo.

\section{Palabras clave}

Posdesarrollo; comunicación; decolonialidad; decrecimiento; medios de comunicación

\begin{abstract}
Dystopia, "fictitious representation of a future society with negative characteristics that cause human alignment" (Royal Academy of the Spanish Language). This is the word that Manuel Chaparro, with mathematical precision, chooses for the title of his work: "Keys to rethink the media and the world we inhabit. The dystopia of development". For the author, development is much more than a term, it is an entire complex system whose dystopian character is unmasking through the pages of this book, which offers us a perspective of analysis of reality and the evolution that we have had as a civilization from the field of communication. A book that tells us about how information and communication have built, disseminated and implemented the imaginaries of the Development Model.
\end{abstract}

\section{Keywords}

Post-development; communication; decoloniality; decrease; media 


\section{Claves para repensar los medios y el mundo que habitamos}

Distopía, "representación ficticia de una sociedad futura de características negativas causantes de la alineación humana" (Real Academia de la Lengua Española). Esta es la palabra que Manuel Chaparro, con matemática precisión, escoge para el título de su obra: "Claves para repensar los medios y el mundo que habitamos. La distopía del desarrollo". Para el autor desarrollo es mucho más que un término, se trata de todo un sistema complejo cuyo carácter distópico va desenmascarando a través de las páginas de este libro, que nos ofrece una perspectiva de análisis de la realidad y la evolución que hemos tenido como civilización desde el ámbito de la comunicación. Un libro que nos habla de cómo la información y la comunicación han construido, difundido e implantado los imaginarios del Modelo de Desarrollo.

Las connotaciones positivas del desarrollo se van esfumando a medida que uno se sumerge en los 14 capítulos de esta "distopía" repleta de argumentaciones ejemplificadas de los males del conocido como Modelo del Desarrollo, un término que no define a sociedades que se valoran, son felices y viven con dignidad, como nos han hecho creer todos estos años, al contrario, se trata de una palabra amable, usada para camuflar todo un modelo socioeconómico orquestado por las élites a nivel mundial para mantener e incrementar sus ya inalcanzables privilegios a costa del resto de la humanidad y del planeta. En nuestras sociedades, el nivel de desarrollo es equivalente al nivel de capacidad de consumo y el consumo es considerado garantía de felicidad, con estos medidores para definir la "buena vida", ¿̇cómo no va a ser un fracaso nuestra sociedad?, plantea Chaparro.

El desarrollo y el empeño por "desarrollar" a todos los pueblos del planeta fue "una idea creada por el capital, vendida al gobierno más poderoso y transferida al mundo con una hábil campaña de propaganda construida desde los medios e implantada, finalmente, en nuestro sistema educativo" (25). La idea de desarrollar no era implantar modelos democráticos en otros países, era exportar modelos de consumo. Así es como el autor define "desarrollar", y esto es lo que va descubriendo este libro, entre otros tantos planteamientos vendidos como verdades incuestionables durante décadas.

Partiendo de una idea cuasi revolucionaria, "Claves para repensar los medios y el mundo que habitamos" se adentra en la compleja pero necesaria tarea de cuestionar el modo de vida que tenemos, el modelo de producción y consumo, mostrado como una idea imbatible, sin alternativas, aceptada sin cuestionamientos. Y este libro es el compendio de argumentos necesarios para derribar la fe ciega en este sistema, sus razonamientos son tan arrolladores, reales y numerosos que no dejan espacio para la duda: el Desarrollo es un modelo distópico y fallido.

La crítica a la Comunicación para el Desarrollo es pilar del libro, que se articula en torno al análisis del comportamiento de los grandes medios de masas que se han puesto al servicio del modelo y que "han dirigido nuestros actos sin que como seres inteligentes hayamos sido capaces de definir el destino que estábamos fabricando", desdibujando todo lo que debía parecer obvio, imponiendo criterios e ideas sin dar pie a la reflexión (25). Los medios, cuenta el libro, han vendido el Desarrollo como vía única para alcanzar el bienestar general al que todos los países y sociedades debían aspirar, pero la realidad, si se analiza con una mirada crítica alejada del enfoque del discurso de los conglomerados mediáticos, tal y como lo hace Chaparro, no es sino favorecer al mercado y al capital, a las todopoderosas élites mundiales.

Este libro es toda una declaración de intenciones: hay que empezar a llamar a las cosas por su nombre. Porque como bien decía Albert Camus, "nombrar mal las cosas es aumentar las desgracias del mundo", y como la obra nos va descubriendo, durante décadas los medios han ocultado e ignorado las implicaciones y consecuencias de un modelo inhumano y ecocida. La aplicación de las políticas del desarrollo generaría "desigualdades, hambrunas, pandemias y guerras, nunca antes conocidas" (59), adelantaba en 2015.

Pero el libro de Manuel Chaparro es más que una crítica, narrado en un formato amable, permitirá a las y los lectores de esta obra realizar un completo paseo histórico, cultural y geográfico a través de nuestro mundo más reciente. Una crítica al desarrollo que atrae como un libro de viajes serpenteando entre metáforas y leyendas como las del Shapstico o Chulla Chaqui amazónico o la Raflexia o flor gigante de Sumatra, entre muchas otras. A menudo el libro se sumerge en las luchas, muchas de ellas derrotas, de los habitantes de Yibuti, pueblo nómada que el desarrollo expulsó de su propio modo de vida; o los habitantes de las áridas tierras del Kalahari completamente adaptados al desierto; los bosquimanos o khoi-san; la noción nómada Pacahuara de la selva amazónica boliviana; el pueblo guaraní-Kaiowá habitante de Mato Grosso do Sul en Brasil; o el pueblo Maká expulsado de sus tierras en el Charo Boreal Paraguayo en pro del desarrollo, entre muchas otras a lo largo de América, Asia, África y también Europa.

"La distopía del desarrollo" es también un viaje histórico desde el nacimiento del modelo que moldea nuestras vidas como fórmula para ampliar los mercados y el acceso a materias primas por parte 
de EE.UU. a finales de los años 40 del siglo pasado hasta los "golpes" a gobiernos democráticos en Guatemala, Honduras o Paraguay, pero también en Irán e Irak. Sobre cómo Nixon sentó las bases para un gobierno mundial en mano de las corporaciones y conglomerados empresariales, pasando por rememorar el histórico Discurso del Estado de la Nación del presidente Truman en enero de 1949, y retrotrayéndonos incluso al nacimiento del capitalismo mismo y la colonización por Occidente del mundo, allá por el siglo XVI. También hay sitio para los postulados del Club de Roma en los 70, los fracasos de las distintas cumbres internacionales como la prometedora de Río 1992, los revolucionarios discursos del Che Guevara o el Informe Brutland de 1987, hasta el manifiesto ¡última Llamada! de 2014.

Para todo ello Chaparro recoge las teorías de aquellas mentes más críticas con la comunicación para el desarrollo y sus herramientas internacionales como el Fondo Monetario Internacional (FMI), el Banco Mundial (CM) o la Organización Mundial del Comercio (OMC): Georgescu-Roegen, el primer economista que abordó la economía desde una perspectiva ecosocial; Antonio Pasquali y Luis Ramiro Beltrán, con las propuestas y cuestionamientos críticos de mayor calado en América Latina; Paulo Freire, que nunca tuvo al desarrollo entre sus objetivos para alcanzar a través de la comunicología de la liberación; Abraham Moles y la ecología de la comunicación; Adorno y Horkheimer, abanderados de la Escuela de Frankfurt, que criticaban la reproducción del discurso de los medios enfocado al entretenimiento banal y consumista para ejercer control ya en 1947; J.P. Warnier y la teoría de la "coca-colonización" e Iván lliich y sus ideas para desescolarizar la sociedad. En definitiva, un recorrido por las y los representantes y las ideas más poderosas de la Escuela Crítica de la Comunicación, en el que también tienen hueco Bordenave, Martín Barbero, Canclini, Rafael Roncagliolo, Marqués de Melo, Washington Uranga, Mario Kaplún o Rosa María Alfaro, entre otros.

El libro se compone de 14 capítulos y arranca con una primera parte que narra el origen del Modelo de Desarrollo, adentrándose en su cromosoma y la estrategia de exportación a otros países. El capítulo tercero se sitúa en las consecuencias de la implantación del modelo de consumo occidental en aquellas sociedades con modelos socioeconómicos no basados en el consumo material, especialmente en América Latina. Las teorías de la comunicación y el desarrollo, así como aquellas teorías críticas con el desarrollo protagonizan la segunda parte. Los capítulos 10 y 11 se centran en la democratización de los discursos, los medios de comunicación reales, el periodismo cívico y ciudadano. La siguiente parte se configura como un pequeño pero completo compendio con tics para informar, comunicar y denunciar la realidad diaria del desarrollo. El libro termina con un capítulo que recoge algunos de los nuevos imaginarios para la construcción de una nueva conciencia común, como el decrecimiento, el "buen vivir" o los principios de la bioeconomía. La conclusión final viene de la necesidad de emprender el camino hacia una comunicación ecosocial, para el posdesarrollo o el decrecimiento.

"Claves para repensar los medios y el mundo que habitamos. La distopía del Desarrollo" es un referente imprescindible, no sólo en el ámbito de la comunicación y los medios, sino para entender el mundo en el que vivimos, para poner cara a la crisis humanitaria y ecológica que la humanidad transita. Es hora de cuestionarse este modelo, las señales son claras, estamos al borde del precipicio: tasas de desigualdad inauditas en la historia de la humanidad y en crescendo; cambio climático; destrucción de la biodiversidad... Toca escribir nuevos caminos.

El libro de Manuel Chaparro no se queda en una mera crítica al modelo, se configura además como un compendio de alternativas de pensamiento y prácticas viables que trabajan de manera circular y equitativa, promoviendo una vida basada en necesidades reales, con un reparto igualitario de las riquezas producidas y en armonía con el planeta y el resto de seres que lo cohabitan. Los discursos son claros, y el contexto demuestra que los preceptos que se narran en este libro son una constante que cada vez nos acerca más a la debacle ecológica y civilizatoria. El mensaje de Manuel Chaparro es preciso y necesario: es imprescindible dejar de usar la comunicación para "transferir modos, estilos de vida y hábitos de consumo que arruinan la vida" (124). 